ReView

\title{
Molecular basis for regulating seasonal reproduction in vertebrates
}

\author{
Taeko Nishiwaki-Ohkawa1,2 and Takashi Yoshimura1,2,3,4 \\ 1Laboratory of Animal Physiology, Graduate School of Bioagricultural Sciences, Nagoya University, \\ Nagoya, Japan \\ 2Institute of Transformative Bio-Molecules (WPI-ITbM), Nagoya University, Nagoya, Japan \\ 3Division of Seasonal Biology, National Institute for Basic Biology, Okazaki, Japan \\ ${ }^{4}$ Avian Bioscience Research Center, Graduate School of Bioagricultural Sciences, Nagoya University, \\ Nagoya, Japan
}

Correspondence should be addressed to T Yoshimura

Email

takashiy@agr.nagoya-u.ac.jp

\begin{abstract}
Animals that inhabit mid- to high-latitude regions exhibit various adaptive behaviors, such as migration, reproduction, molting and hibernation in response to seasonal cues. These adaptive behaviors are tightly regulated by seasonal changes in photoperiod, the relative day length vs night length. Recently, the regulatory pathway of seasonal reproduction has been elucidated using quail. In birds, deep brain photoreceptors receive and transmit light information to the pars tuberalis in the pituitary gland, which induces the secretion of thyroid-stimulating hormone. Thyroid-stimulating hormone locally activates thyroid hormone via induction of type 2 deiodinase in the mediobasal hypothalamus. Thyroid hormone then induces morphological changes in the terminals of neurons that express gonadotropin-releasing hormone and facilitates gonadotropin secretion from the pituitary gland. In mammals, light information is received by photoreceptors in the retina and neurally transmitted to the pineal gland, where it inhibits the synthesis and secretion of melatonin, which is crucial for seasonal reproduction. Importantly, the signaling pathway downstream of light detection and signaling is fully conserved between mammals and birds. In fish, the regulatory components of seasonal reproduction are integrated, from light detection to neuroendocrine output, in a fish-specific organ called the saccus vasculosus. Various physiological processes in humans are also influenced by seasonal environmental changes. The findings discussed herein may provide clues to addressing human diseases, such as seasonal affective disorder.
\end{abstract}

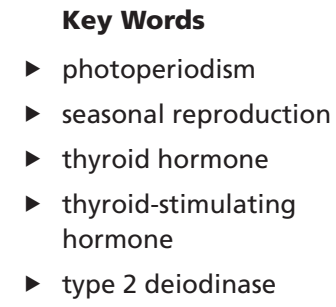

Journal of Endocrinology (2016) 229, R117-R127

\section{Introduction}

In mid- to high-latitude regions of the world, environmental factors such as temperature, day length and precipitation drastically change throughout the year. Organisms living in these regions anticipate seasonal changes using intrinsic timing mechanisms and adapt their physiology to the forthcoming seasons. In chipmunks, for example, seasonal hibernation is regulated by a circannual clock that oscillates with a period of approximately 1 year (Kondo et al. 2006). Many organisms use photoperiod, or relative day length, as a cue to initiate seasonal adaptations. The circadian

This article is adapted from work presented at the European Biological Rhythms Society (EBRS)/World Congress of Chronobiology (WCC) meeting, 2-6 August 2015

The meeting was supported in part by the Journal of Endocrinology.04/26/2023 06:25:31AM 
clock, an oscillator with a period of approximately $24 \mathrm{~h}$, is thought to be responsible for measuring the day length in a phenomenon called photoperiodism (Bünning 1969). Many biological processes are photoperiodic, for example, flowering and dormancy in plants (Heino et al. 2010, Izawa 2010, Putterill et al. 2010), as well as reproduction, diapause (Saunders 2010), migration (Saunders 2010) and molting (Fischer et al. 2008) in animals. Here, we focus on the mechanisms underlying photoperiodic regulation of reproduction in vertebrates, in which this phenomenon has been extensively studied.

\section{Seasonal reproduction in animals}

Reproductive mechanisms in animals can be classified into two categories: seasonal and nonseasonal reproduction. Nonseasonal reproduction is mainly observed in animals inhabiting tropical areas, where annual environmental changes are relatively small. Animals in these areas exhibit reproductive behavior all year round. In contrast, seasonal breeders develop gonads and display reproductive behavior during specific times of the year in order to limit the delivery of offspring between spring and early summer. These seasons are optimal for raising offspring because the climate is moderate and sufficient food is available. A critical factor in determining the timing of mating is the length of the period of gestation or incubation of fertilized eggs (Lincoln \& Short 1980).

Animals can be categorized as long-day (LD) breeders and short-day (SD) breeders based on when they are fertile relative to day length. LD breeders are fertile during spring when the days are longer, whereas SD breeders display reproductive behaviors during autumn when the day length shortens. For example, the breeding behavior of birds and rodents is observed from spring to early summer because their incubation/gestation period lasts only a few weeks. Similarly, mating of large animals with gestation periods of approximately 1 year also occurs in spring. However, SD breeders, such as goats and sheep, with gestation periods of approximately half a year breed during autumn and early winter.

The critical day length refers to the threshold value of light phase duration that is required to trigger a photoperiodic response. Reproductive behaviors in LD breeders are observed when the light phase lasts longer than the critical day length and vice versa in SD breeders (Bünning 1969). During the process of domestication, animals that show a nonseasonal reproduction phenotype have been artificially selected because of their higher yield of offspring and animal products. Therefore, understanding the mechanism of seasonal reproduction will contribute to increased productivity in livestock farming (Lincoln \& Short 1980). In this review, we first describe the current knowledge of the regulatory mechanism of seasonal reproduction from studies using Japanese quail as an avian model. Secondly, we show that a similar mechanism exists in mammals and fish. We conclude with a discussion about the evolution of seasonal reproduction.

\section{Roles and metabolic pathway of thyroid hormone}

Thyroid hormone (TH) is a tyrosine-based hormone that was originally known to promote the maturation of juvenile animals and maintain the basal metabolic rate (Joseph-Bravo et al. 2015). There has been increasing evidence that $\mathrm{TH}$ is responsible for seasonal reproduction (Dawson et al. 2001). Furthermore, removal of the thyroid gland prevents seasonal development/regression of gonads in several avian species and in sheep (Moenter et al. 1991, Dawson 1993, 1998, Parkinson \& Follett 1995). Administration of $\mathrm{TH}$ ameliorates the effect of thyroidectomy and mimics exposure to light conditions that induce gonadal development (Follett \& Nicholls 1985, Goldsmith \& Nicholls 1992, Wilson \& Reinert 2000).

It is well established that $\mathrm{TH}$ negatively regulates its own production through the hypothalamic-pituitarythyroid (HPT) axis. Thyrotropin-releasing hormone (TRH) secreted from the hypothalamus induces the pars distalis of the anterior pituitary gland to release thyroidstimulating hormone (TSH), which in turn stimulates the thyroid gland to synthesize and release TH. Thyroxine $\left(\mathrm{T}_{4}\right)$ and 3,5,3'-triiodothyronine $\left(\mathrm{T}_{3}\right)$ are the precursor and active forms of THs, respectively (Fig. 1) (JosephBravo et al. 2015). Both $\mathrm{T}_{4}$ and $\mathrm{T}_{3}$ are produced in the follicle cells of the thyroid gland by proteolytic liberation from thyroglobulin, a large iodinated glycoprotein, and released into circulation (Dunn \& Dunn 2004). In target tissues, THs are transported across the membrane into cells by transporter proteins, such as monocarboxylate transporter 8 (MCT8) (Friesema et al. 2003, Herwig et al. 2009) and organic anion-transporting peptide 1c1 (Oatp1c1) (Abe et al. 2002, Hagenbuch \& Meier 2004). Once inside the cell, $\mathrm{T}_{4}$ is converted into active $\mathrm{T}_{3}$ by type 2 deiodinase (DIO2) by elimination of an iodine residue at the $5^{\prime}$ position (Fig. 1). DIO2 locally activates TH at the cellular level without affecting the HPT axis.

Published by Bioscientifica Ltd. 


\section{Thyroxine $\left(T_{4}\right)$}<smiles>N[C@@H](Cc1cc(I)c(Oc2cc(I)c(O)c(I)c2)c(I)c1)C(=O)O</smiles>

\section{3,5,3'-triiodothyronine $\left(\mathrm{T}_{3}\right)$}<smiles>N[C@@H](Cc1cc(I)c(Oc2ccc(O)c(I)c2)c(I)c1)C(=O)O</smiles>

\section{3,3'-diiodothyronine $\left(T_{2}\right)$}<smiles>N[C@@H](Cc1ccc(Oc2ccc(O)c(I)c2)c(I)c1)C(=O)O</smiles>

Figure 1

Activation and inactivation of thyroid hormones by iodothyronine deiodinases. Thyroxine $\left(T_{4}\right)$, the thyroid hormone precursor, is converted into the active form, 3,5,3'-triiodothyronine $\left(T_{3}\right)$, by deiodination at the $5^{\prime}$ position mediated by DIO2. DIO3 inactivates $T_{3}$ by releasing the $\mathrm{C}-5$ iodine to form the $T_{2}$.

\section{TH in the mediobasal hypothalamus regulates seasonal reproduction in quail}

Japanese quail (Coturnix japonica) is a LD breeder belonging to the family Phasianidae that includes chicken and pheasant. Gonadal development and regression in quail shows a clear photoperiodic response. Under SD conditions, gonads are kept undifferentiated; however, 1 day after transfer into LD conditions, serum gonadotropin levels increase and within 2 weeks, and the weight of testis increases by 100 times. Interestingly, continuous illumination during the daytime is not necessary, but a light pulse during the critical time window (photoinducible phase) is sufficient to induce a photoperiodic response. In quails, $15 \mathrm{~min}$ of light given $14 \mathrm{~h}$ after dawn triggers gonadal development (Follett \& Sharp 1969). The mediobasal hypothalamus (MBH) is thought to be the regulatory center for seasonal reproduction in birds. $\mathrm{MBH}$ lesions block light-induced gonadal development even under LD conditions (Sharp \& Follett 1969). Moreover, electrical stimulation of $\mathrm{MBH}$ increases the concentration of LH in plasma (Konishi et al. 1987) and testicular growth (Ohta et al. 1984). Furthermore, c-Fos, a neuronal activation marker, is induced in the $\mathrm{MBH}$ in response to a single LD stimulus (Meddle \& Follett 1995, 1997). Collectively, these phenomena support the notion that the $\mathrm{MBH}$ plays central roles in regulating seasonal reproduction.

In order to identify the components of the photoperiodic signaling cascade, genes differentially expressed in the $\mathrm{MBH}$ between $\mathrm{LD}$ and SD conditions were explored by subtractive hybridization. Expression of the DIO2 gene is significantly induced by a 1-h light pulse during the photoinducible phase (Yoshimura et al. 2003). In contrast to DIO2 induction, expression of type 3 deiodinase gene (DIO3), the product of which inactivates $\mathrm{T}_{3}$ by releasing C-5 iodine (Fig. 1), is repressed under LD conditions (Yasuo et al. 2005). These results suggest that local activation of $\mathrm{TH}$ in the $\mathrm{MBH}$ plays a key role in the regulation of seasonal reproduction. In fact, the concentration of $\mathrm{T}_{3}$ in the $\mathrm{MBH}$ is 10 times higher in LD conditions than in SD conditions (Yoshimura et al. 2003). MBH DIO2 mRNA is localized to the ependymal cells around the third ventricle (Yoshimura et al. 2003). Chronic intraventricular administration of $\mathrm{T}_{3}$ in quail stimulates testicular development even in SD conditions (Yoshimura et al. 2003). These results confirm that the local concentration of $\mathrm{T}_{3}$ at the $\mathrm{MBH}$ is increased by induction and repression of DIO2 and DIO3, respectively, and facilitates photoperiodic gonadal development.

\section{Locally activated TH induces neuronal plasticity in the $\mathrm{MBH}$}

In vertebrates, gonadal development is regulated by the HPG axis. Gonadotropin-releasing hormone (GnRH) is secreted from the hypothalamus and stimulates the release of gonadotropins, such as luteinizing hormone and follicle-stimulating hormone, from the anterior pituitary gland. These hormones act on the testis and ovary to facilitate gonadal development and the production of steroid hormones, including androgen, estrogen and progesterone. Therefore, seasonal breeders activate the HPG axis only in the breeding season.

Published by Bioscientifica Ltd 
$\mathrm{TH}$ is involved in neural development and plasticity in the central nervous system (Bernal 2002), raising the possibility that locally activated $\mathrm{T}_{3}$ in the $\mathrm{MBH}$ promotes the development of testis via modification of neuroendocrine pathways. TH receptors exist in the median eminence of the $\mathrm{MBH}$ where terminals of GnRH neurons project (Yoshimura et al. 2003). Electron microscopy revealed that terminal morphology of GnRH neurons varied according to the photoperiod. GnRH nerve terminals are wrapped with endfeet of glial processes in SD conditions, whereas in LD conditions, the terminals contact the basal lamina of capillary vessels and allow GnRH secretion into the bloodstream (Yamamura et al. 2004). It is possible that these morphological changes induced by MBH-localized $\mathrm{T}_{3}$ allow gonadal development only in LD conditions.

\section{TSH is the master regulator of seasonal reproduction}

In order to elucidate the signaling pathway between light stimulus and $\mathrm{DIO} 2$ induction, the regulatory network of genes activated in the MBH upon light stimulus was analyzed using a chicken genome microarray. Quails housed under SD conditions (6L18D) were transferred to LD conditions (20L4D), and then time series samples of $\mathrm{MBH}$ were subjected to genome-wide expression analysis. At $14 \mathrm{~h}$ after the SD-to-LD transition, a gene encoding the $\beta$-subunit of thyroid-stimulating hormone (TSHB) is induced, and $4 \mathrm{~h}$ later, the expression of a second wave of genes, including DIO2, is increased (Nakao et al. 2008). TSH is a glycoprotein hormone that consists of $\alpha$ - and $\beta$-subunits (Magner 1990, Vassart \& Dumont 1992). TSHB mRNA is localized in the pars tuberalis (PT) (Nakao et al. 2008) of the anterior pituitary gland that surrounds the median eminence. Intracerebroventricular administration of TSH increases the testis size to the same degree as seen in the LD condition (Nakao et al. 2008).

TSH receptor (TSHR) is highly expressed in ependymal cells that coexpress DIO2. These results suggest that induction of TSH in the PT (PT-TSH) triggers a photoperiodic response and stimulates the expression of DIO2. TSHRs are $\mathrm{G}$ protein-coupled receptors that induce genes flanked by cAMP-responsive elements (CREs) via activation of Gso-cAMP signaling pathway (Magner 1990, Vassart \& Dumont 1992, Walton \& Rehfuss 1992). The quail DIO2 gene possesses CRE sequences in its 5 '-flanking region. A luciferase reporter gene containing the $\mathrm{DIO} 2$ upstream region is induced by TSH administration, and mutations in the CRE sequences abolish luciferase expression (Nakao et al. 2008). These results demonstrate that PT-TSH is a master regulatory factor of the photoperiodic response downstream of photoreception.

The induction of TSH in the pars distalis (PD-TSH) of the anterior pituitary is known to stimulate the thyroid gland to synthesize and release $\mathrm{TH}$, which results in increasing basal metabolic rates (Magner 1990, Joseph-Bravo et al. 2015). Uncovering how PT-TSH and PD-TSH avoid functional crosstalk after release into the circulation was an important issue. In mice, PT-TSH and PD-TSH are subjected to tissue-specific glycosylation; PD-TSH contains sulfated biantennary $\mathrm{N}$-glycans and is rapidly degraded in the liver (Magner 1990, Ikegami et al. 2014). However, PT-TSH is modified with sialylated multibranched $\mathrm{N}$-glycans and forms a macro-TSH complex with immunoglobulin or albumin in the blood, which inactivates circulating PT-TSH and prevents stimulation of the thyroid gland (Ikegami et al. 2014).

\section{Photoreceptors regulating avian photoperiodism}

In addition to photoreceptors in the retina, nonmammalian vertebrates have extraretinal photoreceptors located in the pineal gland (Okano et al. 1994) and the brain; deep brain photoreceptors are thought to be responsible for avian photoperiodism (Benoit 1935, Menaker et al. 1970). As expected, photoperiodicity is not disrupted by the removal of the eyes or pineal gland in quail (Siopes \& Wilson 1974). Among the 12 opsin superfamily genes in the chicken genome, OPN5 is localized to the cerebrospinal fluid (CSF)contacting neurons in the hypothalamic paraventricular organ (PVO) (Nakane et al. 2010). Cell bodies of these neurons project dendrites to the third ventricle, and their axons terminate in the vicinity of the PT (Nakane etal. 2010). In Xenopus oocytes with forced OPN5 expression, exposure to light ranging from ultraviolet (UV)-B to blue activates a membrane current under voltage clamp conditions, demonstrating that OPN5 is a short-wavelength-sensitive photopigment (Nakane et al. 2010). Testicular growth is observed in eye-patched, pinealectomized quail upon exposure to light in the UV-to-blue region of spectrum, supporting the hypothesis that OPN5 is a deep brain photoreceptor that regulates photoperiodicity in quail (Nakane et al. 2010). Furthermore, OPN5-positive CSFcontacting neurons in the PVO located in the quail MBH are intrinsically photosensitive (Nakane et al. 2014). The current understanding of the signal transduction pathway for photoperiodicity is summarized in Fig. 2.

Published by Bioscientifica Ltd. 


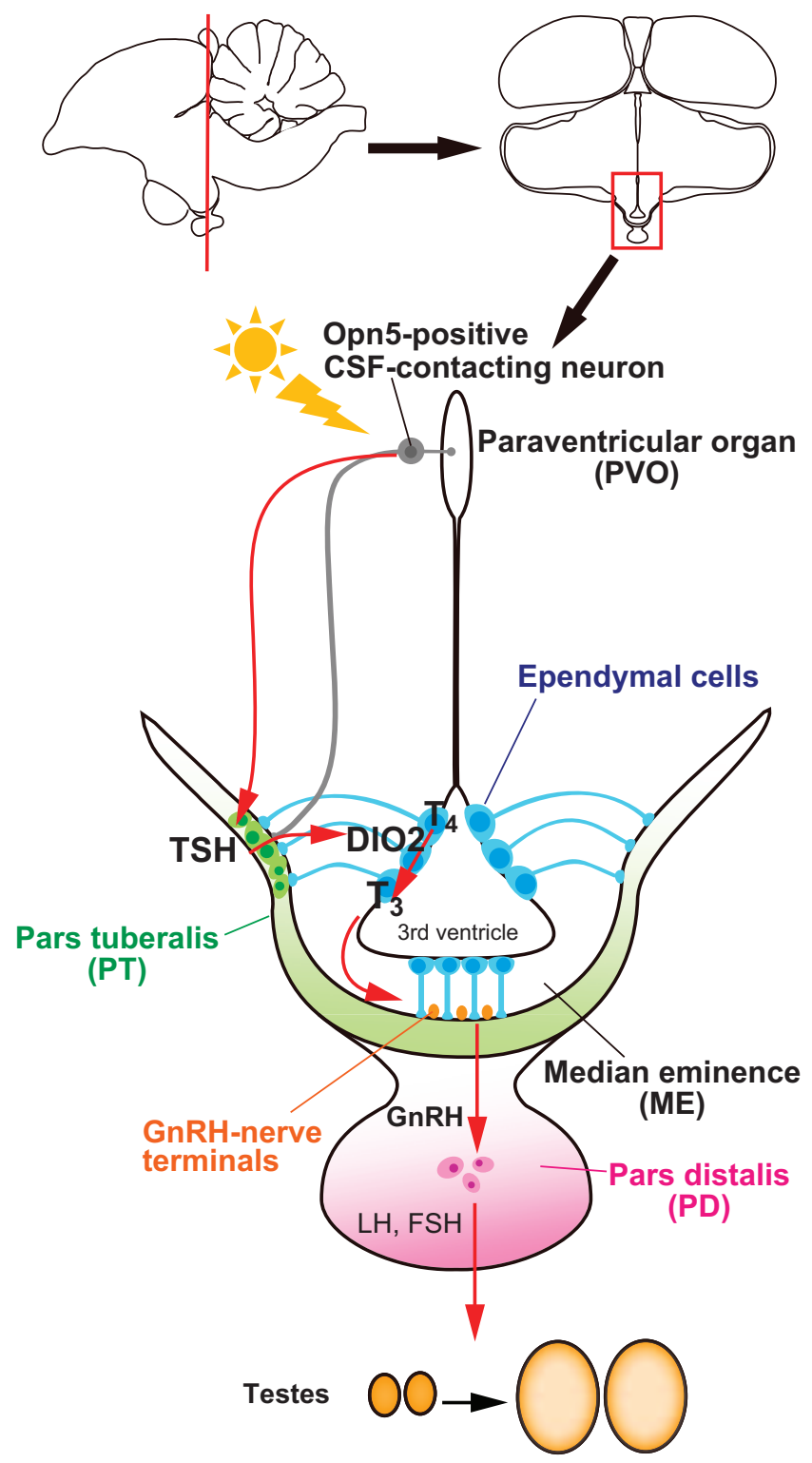

Figure 2

A schematic diagram of the signal transduction cascade for seasonal reproduction in birds. Light information is received by deep brain photoreceptors, such as OPN5, and then transmitted to the pars tuberalis (PT) of the pituitary gland, where TSH is induced. TSH acts on ependymal cells to induce $\mathrm{DIO} 2$, which converts the $\mathrm{TH}$ precursor $\mathrm{T}_{4}$ into the active form $T_{3} . T_{3}$ induces morphological changes in GnRH nerve terminals and glial processes, thereby facilitating GnRH secretion, resulting in gonadal development.

\section{Regulatory mechanism for mammalian seasonal reproduction}

The retina is the only photoreceptive organ in mammals. Light information from the retina is transmitted to the pineal gland via the suprachiasmatic nucleus (SCN), which is the location of the master circadian clock
(Morin et al. 1977). Pinealectomy disrupts photoperiodic responses in reproduction (Pévet 1988), suggesting that the pineal gland relays photoperiodic information. Melatonin is a serotonin-derived hormone produced in the pineal gland (Reiter 1980). Upon synthesis, melatonin is immediately released into circulation. Melatonin synthesis and secretion shows a clear day-night variation with high levels at night and trace amounts during the day (Klein \& Moore 1979), which is directly regulated by arylalkylamine $\mathrm{N}$-acetyltransferase (AANAT) activity in the pineal. AANAT is a rate-limiting enzyme of melatonin synthesis catalyzing acetylation of serotonin, which is rapidly degraded by light exposure (Klein \& Moore 1979). Additionally, the circadian clock activates the transcription of AANAT mRNA during the night via an upstream CRE (Foulkes et al. 1997). Therefore, information regarding environmental light-darkness cycles is physiologically represented by the duration of melatonin synthesis and secretion by the pineal gland.

Melatonin receptors are highly expressed in the PT (Dardente et al. 2003), which is consistent with the notion that melatonin mediates photoperiodic information. LD stimuli induce $\mathrm{DIO} 2$ expression in ependymal cells in hamsters (Watanabe et al. 2004). Intraperitoneal injection with melatonin inhibits $\mathrm{DIO} 2$ expression and regression of the testis even under LD conditions (Watanabe et al. 2004). Although most of inbred mouse lines are genetically deficient in melatonin synthesis, $\mathrm{CBA} / \mathrm{N}$ is one of the few melatonin-proficient strains of mice. In the $\mathrm{CBA} / \mathrm{N}$ mouse brain, expression of TSHB and DIO2 is upregulated by exposure to long light periods (Ono et al. 2008). Although these genes are not photoperiodically regulated and they are not increased even under LD conditions in the melatonin-deficient C57BL/6J strain, intraperitoneal injection of melatonin reduces the expression of TSHB and DIO2 (Ono et al. 2008). Moreover, $D I O 2$ inhibition by melatonin injection is not observed in a TSHR-deleted strain (Ono et al. 2008), nor in melatonin receptor MT1 null mice (Yasuo et al. 2009). It is important to note that the phototransduction mechanism is different in mammals and birds, but the downstream signaling pathway regulating seasonal reproduction is conserved among avian and mammalian species (Fig. 3). TSHB functions as a master control gene of seasonal reproduction in both mammals and birds.

$\mathrm{TH}$ is involved in seasonal reproduction also in SD breeding mammals. In Saanen goats (Capra hircus), DIO2 expression and $\mathrm{T}_{3}$ content in the $\mathrm{MBH}$ are suppressed in LD conditions, which is opposite to the LD breeders (Yasuo et al. 2006). By contrast, PT-TSH expression in

Published by Bioscientifica Ltd. 
A

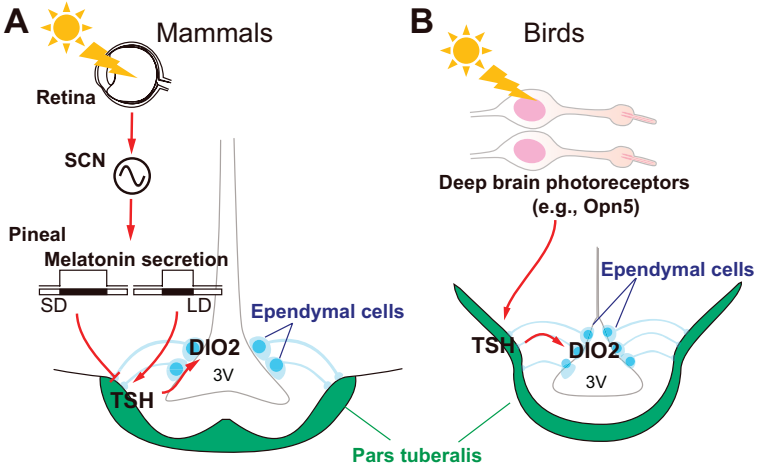

Figure 3

Universality and diversity of photoperiodic signaling mechanisms in vertebrates. In mammals, light information received in the retina is transmitted to the pineal gland via the SCN, the location of the master circadian clock. Melatonin synthesis and secretion in the pineal gland is a reflection of photoperiod, because light and the circadian clock regulate its production, which is higher in the night than in the day. Melatonin inhibits the induction of TSH in the PT; therefore, the signaling cascade downstream of TSH is activated only under long-day conditions (A). In birds, light signals received by deep brain photoreceptors directly induce TSH in the PT (B). In fish, the entire photoperiodic signaling machinery is integrated in the coronet cells located in the fish-specific SV (C).
Soay sheep (Ovis aries) is stimulated under LD conditions followed by DIO2 expression in MBH (Hanon et al. 2008). The photoperiodic TSH-TH signaling pathway is widely conserved; however, the downstream events may be different among species.

Kisspeptin and RFRPs (RFamide-related peptides), which belong to the RFamide superfamily, are involved in the regulation of reproductive activity (Tsutsui et al. 2010). Kisspeptin stimulates $\mathrm{GnRH}$ release via G protein-coupled receptor GPR54 located at the surface of GnRH neurons resulting in activation of the HPG axis (Oakley et al. 2009). In LD breeding rodents, melatonin inhibits secretion of kisspeptin from the hypothalamic arcuate nucleus (Revel et al. 2006, Ansel et al. 2010), and administration of kisspeptin restores the reproductive activity in SD conditions (Revel et al. 2006, Ansel et al. 2011). RFRP-1 and -3 peptides were originally identified as mammalian orthologs of gonadotropin inhibitory hormone $(\mathrm{GnIH})$ that inhibits the HPG axis in birds (Tsutsui et al. 2013). In mammals, the effects of RFRPs on seasonal reproduction are different among species. Administration of RFRP-3 inhibits the activity of GnRH neurons in sheep (Clarke et al. 2008), whereas in Syrian hamsters, RFRP-3 stimulates GnRH secretion under the control of melatonin (Ancel et al. 2012). In Siberian hamsters, the effect of central administration of RFRP peptide is dependent on the photoperiod; it inhibits and stimulates LH release in LD and SD conditions, respectively (Ubuka et al. 2012). It is controversial whether these peptides are the primary targets of inhibitory melatonin signaling or the indirect ones located at the downstream of TSH-TH signaling cascade (Simonneaux et al. 2013). Further studies are required to clarify this issue.

In the photoresponsive rat strain Fischer 344, the retinoic acid (RA) signaling pathway is also activated in LD conditions (Helfer et al. 2012, Tavolaro et al. 2015).
As the temporal expression profiles of TH signaling- and RA signaling-related genes are similar (Tavolaro et al. 2015), it is possible that these two pathways coordinately regulate seasonal reproduction.

\section{Regulation of seasonal reproduction in fish}

Seasonal reproduction is widely observed in fish. For example, medaka is an LD breeder that develops gonads from spring to summer (Koger et al. 1999). Salmonidae fish are SD breeders that swim upstream to their home river in autumn for spawning. Despite lacking an anatomical site homologous to PT, TH is known to affect the reproduction of fish (Cyr et al. 1988). In masu salmon, TSHB and DIO2 mRNAs were localized in the saccus vasculosus (SV), a circumventricular organ located caudal to the pituitary gland (Nakane et al. 2013). The removal of SV results in loss of photoperiodicity, which confirms that SV functions as a regulatory center for seasonal reproduction (Nakane et al. 2013). The photoreceptor that is responsible for photoperiodicity had long been unknown in fish. The removal of the eyes and pineal gland has limited effect on photoperiodicity, suggesting that deep brain photoreceptors might also exist in fish (Borg 2010). As expected, four rhodopsin family genes, RH1, SWS1, LWS and OPN4 are expressed in the SV (Nakane et al. 2013). The SV consists of coronet cells, CSF-contacting cells and supporting cells. Coronet cells have a crown-like morphology with globule-tipped cilia protruding from cell bodies (Fig. 3). Within coronet cells, the TSH $\beta$, SWS1 and OPN4 proteins are localized in the globules of cilia, whereas DIO2 protein is expressed in cell bodies (Nakane et al. 2013), indicating that light information received at the globules regulates expression of TSH and DIO2.

Published by Bioscientifica Ltd. 
Although the regulation of seasonal reproduction seems to be conserved in vertebrates, the anatomical regions responsible for photoperiodic signal transduction differ across the classes of vertebrates. The mammalian photoperiodic response is initiated by light signals received by the retina, which are then transmitted to the hypothalamus where TSH secretion and TH activation by DIO2 take place. In birds, photoreception as well as TSH secretion and DIO2 induction also occur in the hypothalamus. In fish, which are evolutionarily lower than mammalian and avian species, all components of the photoperiodic signaling are integrated into a single anatomical region, the SV. This is analogous to the functional differences in the pineal gland for circadian systems. The mammalian pineal gland is an endocrine organ that synthesizes and releases melatonin under the control of photic input from the retina and the circadian clock in the SCN (Morin et al. 1977), whereas the pineal gland of nonmammalian species contains an entire circadian clock system consisting of the input (photoreceptor), oscillator (circadian clock), and output (synthesis and release of melatonin) (Takahashi et al. 1980, Menaker \& Wisner 1983). It is interesting to note that a recent developmental study identified common transcription factors in the SV and pituitary gland of rainbow trout (Maeda et al. 2015).

\section{Measurement of day length using the circadian clock}

The idea that the circadian clock is involved in the photoperiodic regulation of seasonality was first proposed over 50 years ago (Bünning 1960). This has since been demonstrated to be true in both whitecrowned sparrow (Follett et al. 1974) and quail (Follett \& Sharp 1969), where the photoinducible phase occurs in a circadian manner. However, how the circadian clock determines the specific photoinducible phase remains elusive. Historically, researchers have proposed two theories: the internal and the external coincidence models (Pittendrigh et al. 1972). In the external coincidence model, the photoinducible phase is determined by a circadian oscillator, and light entrains the oscillations as well as triggers the photoperiodic response. However, the internal coincidence model predicts that photoperiodic responses are induced when two or more oscillations are in a certain phase relationship. In this model, light serves only to entrain oscillations. It is widely accepted that the circadian clock generates an oscillation with a period of approximately $24 \mathrm{~h}$ by a transcriptional-translational feedback loop, in which translational products of clock genes inhibit their own transcription (Hardin \& Panda 2013).

In mammals, photoperiodicity is likely regulated by the circadian clock located in the SCN, because lesions of the SCN disrupt photoperiodic responses (Rusak \& Morin 1976). In mammals and birds, the core oscillator of the circadian clock is composed of the clock genes Period (Per), Cryptochrome (Cry), Bmal1 and Clock. These genes are expressed rhythmically not only in the SCN but also in brain regions responsible for photoperiodicity, such as the MBH, PT and pineal gland (Yasuo et al. 2003, Johnston et al. 2005, Tournier et al. 2007). Changes in photoperiod affect the phase relationship between the expression profiles of ovine Per1 and Cry 1 in the SCN and PT, implying that these genes function as an internal coincidence timer (Lincoln et al. 2002); however, this is not the case in mice (Ikegami et al. 2013). Furthermore, disruption of Per2 abolishes rhythmic locomotor activity and the expression of other clock genes, but it does not affect photoperiodic induction of Tshb, Dio2 and Dio3 (Ikegami et al. 2013). Therefore, further studies are necessary to fully elucidate the involvement of not only known clock genes but also novel clock factors in the photoperiodic time measurement.

To achieve this, a chemical biology approach might be useful. Recently, small molecules that affect circadian parameters, such as period and amplitude, have been identified by cell-based high-throughput chemical library screening (Wallach \& Kramer 2015). By this method, small compounds that lengthen the circadian period by acting directly on the clock protein CRY have been discovered (Hirota et al. 2012). We have extended this study by performing structure-activity relationship (SAR) analyses, and as a result, we have developed novel period-shortening molecules (Oshima et al. 2015). Clock-modulating compounds might be useful tools to understand how the circadian clock regulates seasonal reproduction by in vivo administration of these molecules. Moreover, these compounds might be applied to treatment of human seasonal disorders, such as seasonal affective disorder (SAD, see next).

\section{Seasonal rhythms in humans}

Various physiological activities in humans show seasonal fluctuations. Temporal profiles of more than 4000

Published by Bioscientifica Ltd 
protein-coding mRNAs in white blood cells and adipose tissue show seasonal variations, which differ between Europeans and Africans. Expression of genes related to immunity and risk biomarkers for cardiovascular and psychiatric diseases increase in winter in Europeans (Dopico et al. 2015).

SAD is a disease that is characterized by depressionlike symptoms from autumn to winter with remission or slight hypomania from spring to summer (Rosenthal et al. 1984). A recent study revealed more frequent depression-like behavior in mice kept in SD conditions compared with those kept in LD conditions (Otsuka et al. 2014). The level of serotonin in the brain is also decreased in LD conditions (Otsuka et al. 2014). Together, these results raise the possibility that the mouse model recapitulates human seasonal affective disorder. The relationship between $\mathrm{TH}$ and depression has long been discussed (Wiersinga 2014); therefore, understanding the mechanism that animals use to sense seasonal changes may help humans address and possibly treat seasonal disorders.

\section{Concluding remarks}

Studies in the past two decades have uncovered an evolutionarily conserved mechanism for photoperiodic signal transduction. At the same time, species-specific aspects have also become apparent. These findings have contributed to a greater understanding of seasonal reproduction and photoperiodism, and might be useful in developing strategies to increase animal production in livestock farming, as well as therapies for human seasonal disorders. Additional interdisciplinary approaches, such as chemical biology or molecular epidemiology, might also be helpful in achieving these aims.

\section{Declaration of interest}

The authors declare that there is no conflict of interest that could be perceived as prejudicing the impartiality of this review.

\section{Funding}

This work was supported by the JSPS KAKENHI Grant Number 26000013, Human Frontier Science Program (RGP0030/2015).

\section{Acknowledgment}

We thank Dr Kathy Tamai for comments on the manuscript.

\section{References}

Abe T, Suzuki T, Unno M, Tokui T \& Ito S 2002 Thyroid hormone transporters: recent advances. Trends in Endocrinology and Metabolism 13 215-220. (doi:10.1016/S1043-2760(02)00599-4)

Ansel L, Bolborea M, Bentsen AH, Klosen P, Mikkelsen JD \& Simonneaux V 2010 Differential regulation of kiss1 expression by melatonin and gonadal hormones in male and female Syrian hamsters. Journal of Biological Rhythms 25 81-91. (doi:10.1177/0748730410361918)

Ansel L, Bentsen AH, Ancel C, Bolborea M, Klosen P, Mikkelsen JD \& Simonneaux V 2011 Peripheral kisspeptin reverses short photoperiod-induced gonadal regression in Syrian hamsters by promoting GnRH release. Reproduction 142 417-425. (doi:10.1530/ REP-10-0313)

Ancel C, Bentsen AH, Sébert ME, Tena-Sempere M, Mikkelsen JD \& Simonneaux V 2012 Stimulatory effect of RFRP-3 on the gonadotrophic axis in the male Syrian hamster: the exception proves the rule. Endocrinology 153 1352-1363. (doi:10.1210/ en.2011-1622)

Benoit J 1935 Le role des yeux dans l'action stimulante de la lumiere sure le developpement testiulaire chez le canard. Comptes Rendus des Séances et Mémoires de la Société de Biologie 118 669-671.

Bernal J 2002 Action of thyroid hormone in brain. Journal of Endocrinological Investigation 25 268-288. (doi:10.1007/BF03344003)

Borg B 2010 Phoroperiodism in fishes. In Photoperiodism the Biological Calendar, pp 371-398. Eds Nelson RJ, Denlinger DL \& Somers DE. New York, NY, USA: Oxford University Press.

Bünning E 1960 Circadian rhythms and the time measurement in photoperiodism. Cold Spring Harbor Symposia on Quantitative Biology 25 249-259. (doi:10.1101/SQB.1960.025.01.026)

Bünning E 1969 Common features of photoperiodism in plants and animals. Photochemstry and Photobiology 9 219-228. (doi:10.1111/j.1751-1097.1969.tb07286.x)

Clarke IJ, Sari IP, Qi Y, Smith JT, Parkington HC, Ubuka T, Iqbal J, Li Q, Tilbrook A, Morgan K, et al. 2008 Potent action of RFamide-related peptide-3 on pituitary gonadotropes indicative of a hypophysiotropic role in the negative regulation of gonadotropin secretion. Endocrinology 149 5811-5821. (doi:10.1210/en.2008-0575)

Cyr DG, Bromage NR, Duston J \& Eales JG 1988 Seasonal patterns in serum levels of thyroid hormones and sex steroids in relation to photoperiod-induced changes in spawning time in rainbow trout, Salmo gairdneri. General and Comparative Endocrinology 69 217-225. (doi:10.1016/0016-6480(88)90008-1)

Dardente H, Klosen P, Pévet P \& Masson-Pévet M 2003 MT1 melatonin receptor mRNA expressing cells in the Pars Tuberalis of the European hamster. Journal of Neuroendocrinology 15 778-786. (doi:10.1046/ j.1365-2826.2003.01060.x)

Dawson A 1993 Thyroidectomy progressively renders the reproductive system of starlings (Sturnus vulgaris) unresponsive to changes in daylength. Journal of Endocrinology 139 51-55. (doi:10.1677/ joe.0.1390051)

Dawson A 1998 Thyroidectomy of house sparrows (Passer domesticus) prevents photo-induced testicular growth but not the increased hypothalamic gonadotrophin-releasing hormone. General and Comparative Endocrinology 110 196-200. (doi:10.1006/ gcen.1998.7605)

Dawson A, King VM, Bentley GE \& Ball GF 2001 Photoperiodic control of seasonality in birds. Journal of Biological Rhythms 16 365-380. (doi:10. 1177/074873001129002079)

Dopico XC, Evangelou M, Ferreira RC, Guo H, Pekalski ML, Smyth DJ, Cooper N, Burren OS, Fulford AJ, Hennig BJ, et al. 2015 Widespread seasonal gene expression reveals annual differences in human immunity and physiology. Nature Communications 67000. (doi:10.1038/ncomms8000)

Published by Bioscientifica Ltd. 
Dunn JT \& Dunn AD 2004 Update on intrathyroidal iodine metabolism. Thyroid 11 407-414. (doi:10.1089/105072501300176363)

Fischer TW, Slominski A, Tobin DJ \& Paus R 2008 Melatonin and the hair follicle. Journal of Pineal Research 44 1-15. (doi:10.1111/j.1600079X.2007.00512.x)

Follett BK \& Nicholls TJ 1985 Influences of thyroidectomy and thyroxine replacement on photoperiodically controlled reproduction in quail. Journal of Endocrinology 107 211-221. (doi:10.1677/ joe.0.1070211)

Follett BK \& Sharp PJ 1969 Circadian rhythmicity in phoroperiodically induced gonadotrophin release and gonadal growth in the quail. Nature 223 968-971. (doi:10.1038/223968b0)

Follett BK, Mattocks PW Jr \& Farner DS 1974 Circadian function in the photoperiodic induction of gonadotropin secretion in the whitecrowned sparrow, Zonotrichia leucophrys gambelii. PNAS 71 1666-1669.

Foulkes NS, Whitmore D \& Sassone-Corsi P 1997 Rhythmic transcription: The molecular basis of circadian melatonin synthesis. Biology of the Cell 89 487-494 (doi:10.1016/S02484900(98)80004-X)

Friesema EC, Ganguly S, Abdalla A, Manning Fox JE, Halestrap AP \& Visser TJ 2003 Identification of monocarboxylate transporter 8 as a specific thyroid hormone transporter. Journal of Biological Chemistry 278 40128-40135. (doi:10.1074/jbc.M300909200)

Goldsmith AR \& Nicholls TJ 1992 Thyroxine effects upon reproduction, prolactin secretion and plumage moult in thyroidectomised European starlings Sturnus vulgaris. Ornis Scandinavica 23 398-404. (doi:10.2307/3676666)

Hagenbuch B \& Meier PJ 2004 Organic anion transporting polypeptides of the OATP/SLC21 family: phylogenetic classification as OATP/SLCO superfamily, new nomenclature and molecular/functional properties. Pfluger Arhiv 447 653-665. (doi:10.1007/s00424-003-1168-y)

Hanon EA, Lincoln GA, Fustin JM, Dardente H, Masson-Pévet M, Morgan PJ \& Hazlerigg DG 2008 Ancestral TSH mechanism signals summer in a photoperiodic mammal. Current Biology 18 1147-1152. (doi:10.1016/j.cub.2008.06.076)

Hardin PE \& Panda S 2013 Circadian timekeeping and output mechanisms in animals. Current Opinion in Neurobiology 23 724-731. (doi:10.1016/j.conb.2013.02.018)

Heino P, Nilsson O \& Palva T 2010 Phoroperiodic control of dormancy and flowering in trees. In Photoperiodism the Biological Calendar, pp 88-106. Eds Nelson RJ, Denlinger DL \& Somers DE. New York, NY, USA: Oxford University Press.

Helfer G, Ross AW, Russell L, Thomson LM, Shearer KD, Goodman TH, McCaffery PJ \& Morgan PJ 2012 Photoperiod regulates vitamin A and Wnt/ $\beta$-catenin signaling in F344 rats. Endocrinology 153 815-824. (doi:10.1210/en.2011-1792)

Herwig A, Wilson D, Logie TJ, Boelen A, Morgan PJ, Mercer JG \& Barrett P 2009 Photoperiod and acute energy deficits interact on components of the thyroid hormone system in hypothalamic tanicytes of the Siberian hamster. American Journal of Physiology: Regulatory, Integrative and Comparative Physiology 296 R1307-R1315. (doi:10.1152/ ajpregu.90755.2008)

Hirota T, Lee JW, St John PC, Sawa M, Iwaisako K, Noguchi T, Pongsawakul PY, Sonntag T, Welsh DK, Brenner DA, et al. 2012 Identification of small molecule activators of cryptochrome. Science 337 1094-1097. (doi:10.1126/science.1223710)

Ikegami K, Iigo M \& Yoshimura T 2013 Circadian clock gene Per2 is not necessary for the photoperiodic response in mice. PLOS ONE $\mathbf{8}$ e58482. (doi:10.1371/journal.pone.0058482)

Ikegami K, Liao XH, Hoshino Y, Ono H, Ota W, Ito Y, NishiwakiOhkawa T, Sato C, Kitajima K, Iigo M, et al. 2014 Tissuespecific posttranslational modification allows functional targeting of thyrotropin. Cell Reports 9 801-810. (doi:10.1016/j. celrep.2014.10.006)

Izawa T 2010 Phoroperiodic control of flowering in the short-day plant Oryza sativa. In Photoperiodism the Biological Calendar, pp 38-58. Eds

http://joe.endocrinology-journals.org

DOI: $10.1530 / J O E-16-0066$
(C) 2016 Society for Endocrinology Printed in Great Britain
Nelson RJ, Denlinger DL \& Somers DE. New York, NY, USA: Oxford University Press.

Johnston JD, Francis JP \& Hazlerigg DG 2005 Photoperiod regulates multiple gene expression in the suprachiasmatic nuclei and pars tuberalis of the Siberian hamster (Phodopus sungorus). European Journal of Neuroscience 21 2967-2974. (doi:10.1111/j.14609568.2005.04148.x)

Joseph-Bravo P, Jaimes-Hoy L, Uribe RM \& Charli JL 2015 TRH, the first hypophysiotropic releasing hormone isolated: control of the pituitary-thyroid axis. Journal of Endocrinology 226 T85-T100. (doi:10.1530/JOE-15-0124)

Klein DC \& Moore RY 1979 Pineal N-acetyltransferase and hydroxyindole-O-methyltransferase: control by the retinohypothalamic tract and the suprachiasmatic nucleus. Brain Research 174 245-262. (doi:10.1016/0006-8993(79)90848-5)

Koger CS, Teh SJ \&Hinton DE 1999 Variations of light and temperature regimes and resulting effects on reproductive parameters in medaka (Oryzias latipes). Biology of Reproduction 61 1287-1293. (doi:10.1095/ biolreprod61.5.1287)

Kondo N, Sekijima T, Kondo J, Takamatsu N, Tohya K \& Ohtsu T 2006 Circanual control of hibernation by HP complex in the brain. Cell 125 161-172. (doi:10.1016/j.cell.2006.03.017)

Konishi H, Foster RG \& Follett BK 1987 Evidence for daily rhythmicity in the acute release of luteinizing hormone in response to electrical stimulation in the Japanese quail. Journal of Comparative Physiology A 161 315-319. (doi:10.1007/BF00615251)

Lincoln GA \& Short RV 1980 Nature's contraceptive. Recent Progress in Hormone Research 36 1-52. (doi:10.1016/b978-0-12-5711364.50007-3)

Lincoln G, Messenger S, Andersson H \&Hazlerigg D 2002 Temporal expression of seven clock genes in the suprahiasmatic nucleus and the pars tuberalis of the sheep: evidence for an internal coincidence timer. PNAS 99 13890-13895. (doi:10.1073/pnas.212517599)

Maeda R, Shimo T, Nakane Y, Nakao N \& Yoshimura T 2015 Ontogeny of the saccus vasculosus, a seasonal sensor in fish. Endocrinology $\mathbf{1 5 6}$ 4238-4243. (doi:10.1210/en.2015-1415)

Magner JA 1990 Thyroid-stimulating hormone: biosynthesis, cell biology, and bioactivity. Endocrine Review 11 354-385. (doi:10.1210/edrv-112-354)

Meddle SL \& Follett BK 1995 Photoperiodic activation of fos-like immunoreactive protein in neurons within the tuberal hypothalamus of Japanese quail. Journal of Comparative Physiology A 176 79-89. (doi:10.1007/BF00197754)

Meddle SL \& Follett BK 1997 Photoperiodically driven changes in Fos expression within the basal tuberal hypothalamus and median eminence of Japanese quail. Journal of Neuroscience $\mathbf{1 7}$ 8909-8918.

Menaker M \& Wisner S 1983 Temperature-compensated circadian clock in the pineal of Anolis. PNAS 80 6119-6121. (doi:10.1073/ pnas.80.19.6119)

Menaker M, Roberts R, Elliott J \& Underwood H 1970 Extraretinal light perception in the sparrow. III. The eyes do not participate in photoperiodic photoreception. PNAS 67 320-325. (doi:10.1073/ pnas.67.1.320)

Moenter SM, Woodfill CJ \& Karsch FJ 1991 Role of the thyroid gland in seasonal reproduction: thyroidectomy blocks seasonal suppression of reproductive neuroendocrine activity in ewes. Endocrinology 128 1337-1344. (doi:10.1210/endo-128-3-1337)

Morin LP, Fitzgerald KM, Rusak B \& Zucker I 1977 Circadian organization and neural mediation of hamster reproductive rhythms. Psychoneuroendocrinology 2 73-98. (doi:10.1016/03064530(77)90035-X)

Nakane Y, Ikegami K, Ono H, Yamamoto N, Yoshida S, Hirunagi K, Ebihara S, Kubo Y \& Yoshimura T 2010 A mammalian neural tissue opsin (Opsin 5) is a deep brain photoreceptor in birds. PNAS 107 15264-15268. (doi:10.1073/pnas.1006393107) 
Nakane Y, Ikegami K, Iigo M, Ono H, Takeda K, Takahashi D, Uesaka M, Kimijima M, Hashimoto R, Arai N, et al. 2013 The saccus vasculosus of fish is a sensor of seasonal changes in day length. Nature Communications 4 2108. (doi:10.1038/ncomms3108)

Nakane Y, Shimmura T, Abe H \& Yoshimura T 2014 A Intrinsic photosensitivity of a deep brain photoreceptor. Current Biology $\mathbf{2 4}$ R596-R597. (doi:10.1016/j.cub.2014.05.038)

Nakao N, Ono H, Yamamura T, Anraku T, Takagi T, Higashi K, Yasuo S, Katou Y, Kageyama S, Uno Y, et al. 2008 Thyrotrophin in the pars tuberalis triggers photoperiodic response. Nature 452 317-322. (doi:10.1038/nature06738)

Oakley AE, Clifton DK \& Steiner RA 2009 Kisspeptin signaling in the brain. Endocrine Reviews 30 713-743. (doi:10.1210/er.2009-0005)

Ohta M, Wada M \& Homma K 1984 Induction of rapid testicular growth in Japanese quail by phasic electrical stimulation of the hypothalamic photosensitive area. Journal of Comparative Physiology A 154 583-589. (doi:10.1007/BF00610171)

Okano T, Yoshizawa T \& Fukada Y 1994 Pinopsin is a chicken pineal phoreceptive molecule. Nature 372 94-97. (doi:10.1038/372094a0)

Ono H, Hoshino Y, Yasuo S, Watanabe M, Nakane Y, Murai A, Ebihara S, Korf HW \& Yoshimura T 2008 Involvement of thyrotropin in phoroperiodic signal transduction in mice. PNAS 105 18238-18242. (doi:10.1073/pnas.080895215)

Oshima T, Yamanaka I, Kumar A, Yamaguchi J, Nishiwaki-Ohkawa T, Muto K, Kawamura R, Hirota T, Yagita K, Irle S, et al. 2015 C-H activation generates period-shortening molecules that target cryptochrome in the mammalian circadian clock. Angewandte Chemie International Edition in English 54 7193-7197. (doi:10.1002/ anie.201502942)

Otsuka T, Kawai M, Togo Y, Goda R, Kawase T, Matsuo H, Iwamoto A, Nagasawa M, Furuse M \& Yasuo S 2014 Photoperiodic responses of depression-like behavior, the brains serotonergic system, and peripheral metabolism in laboratory mice. Psychoneuroendocrinology 40 37-47. (doi:10.1016/j.psyneuen.2013.10.013)

Parkinson TJ \& Follett BK 1995 Thyroidectomy abolishes seasonal testicular cycles of Soay rams. Proceedings of the Royal Society B 259 1-6. (doi:10.1098/rspb.1995.0001)

Pévet P 1988 The role of the pineal gland in the photoperiodic control of reproduction in different hamster species. Reproduction Nutrition Development 28 443-458. (doi:10.1051/rnd:19880310)

Pittendrigh CS 1972 Circadian surfaces and the diversity of possible roles of circadian organization in photoperiodic induction. PNAS 69 2734-2737. (doi:10.1073/pnas.69.9.2734)

Putterill J, Stockum C \& Warman G 2010 Phoroperiodic flowering in the long-day plant Arabidopsis thaliana. In Photoperiodism the Biological Calendar, pp 9-37. Eds Nelson RJ, Denlinger DL \& Somers DE. New York, NY, USA: Oxford University Press.

Reiter RJ 1980 The pineal and its hormones in the control of reproduction in mammals. Endocrine Reviews 1 109-131. (doi:10.1210/edrv-1-2-109)

Revel FG, Saboureau M, Masson-Pévet M, Pévet P, Mikkelsen JD \& Simonneaux V 2006 Kisspeptin mediates the photoperiodic control of reproduction in hamsters. Current Biology 16 1730-1735. (doi:10.1016/j.cub.2006.07.025)

Rosenthal NE, Sack DA, Gillin C, Lewy AJ, Goodwin FK, Davenport Y, Mueller PS, Newsome DA \& Wehr TA 1984 Seasonal affective disorder. A description of the syndrome and preliminary finding with light therapy. Archives of General Psychiatry 41 72-80. (doi:10.1001/ archpsyc.1984.01790120076010)

Rusak B \& Morin LP 1976 Testicular responses to photoperiod are blocked by lesions of the suprachiasmatic nuclei in golden hamsters. Biology of Reproduction 13 366-374. (doi:10.1095/biolreprod15.3.366)

Saunders DS 2010 Phoroperiodism in insects: maigration and diapause responces. In Photoperiodism the Biological Calendar, pp 218-257. Eds Nelson RJ, Denlinger DL \& Somers DE. New York, NY, USA: Oxford University Press.
Sharp PJ \& Follett BK 1969 The effect of hypothalamic lesions on gonadotrophin release in Japanese quail (Coturnix coturnix japonica). Neuroendocrinology 5 205-218. (doi:10.1159/000121861)

Simonneaux V, Ancel C, Poirel VJ \& Gauer F 2013 Kisspeptins and RFRP-3 act in concert to synchronize rodent reproduction with seasons. Frontiers in Neuroscience 7 22. (doi:10.3389/fnins.2013.00022)

Siopes TD \& Wilson WO 1974 Extraocular modification of photoreception in intact and pinealectomized coturnix. Poultry Science 53 2035-2041. (doi:10.3382/ps.0532035)

Takahashi JS, Hamm H \& Menaker M 1980 Circadian rhythms of melatonin release from individual superfused chicken pineal glands in vitro. PNAS 77 2319-2322. (doi:10.1073/pnas.77.4.2319)

Tavolaro FM, Thomson LM, Ross AW, Morgan PJ \& Helfer G 2015 Photoperiodic effects on seasonal physiology, reproductive status and hypothalamic gene expression in young male F344 rats. Journal of Neuroendocrinology 27 79-87. (doi:10.1111/jne.12241)

Tournier BB, Dardente H, Simonneaux V, Vivien-Roels B, Pévet P, Masson-Pévet M \& Vuillez P 2007 Seasonal variations of clock gene expression in the suprachiasmatic nuclei and pars tuberalis of the European hamster (Cricetus cricetus). European Journal of Neuroscience 25 1529-1536. (doi:10.1111/j.14609568.2007.05421.x)

Tsutsui K, Bentley GE, Kriegafeld LJ, Osugi T, Seong JY \& Vaudry H 2010 Discovery and evolutionary history of gonadotrophin-inhibitory hormone and kisspeptin: new key neuropeptides controlling reproduction. Journal of Neuroendocrinology 22 716-727. (doi:10.1111/ j.1365-2826.2010.02018.x)

Tsutsui K, Ubuka T, Bentley GE \& Kriegfeld LJ 2013 Review: regulatory mechanisms of gonadotropin-inhibitory hormone ( $\mathrm{GnIH})$ synthesis and release in photoperiodic animals. Frontiers in Neuroscience $\mathbf{7} 60$. (doi:10.3389/fnins.2013.00060)

Ubuka T, Inoue K, Fukuda Y, Mizuno T, Ukena K, Kriegsfeld LJ \& Tsutsui K 2012 Identification, expression and physiological functions of Siberian hamster gonadotropin-inhibitory hormone. Endocrinology 153 373-385. (doi:10.1210/en.2011-1110)

Vassart G \& Dumont JE 1992 The thyrotropin receptor and the regulation of thyrocyte function and growth. Endocrine Reviews 13 596-611. (doi:10.1210/edrv-13-3-596)

Wallach T \& Kramer A 2015 Chemical chronobiology: toward drugs manipulating time. FEBS Letters 589 1530-1538. (doi:10.1016/ j.feblet.2015.04.059)

Walton KM \& Rehfuss RP 1992 Molecular mechanisms of cAMP-regulated gene expression. Molecular Neurobiology 9 197-210. (doi:10.1007/ BF02780341)

Watanabe M, Yasuo S, Watanabe T, Yamamura T, Nakao N, Ebihara S \& Yoshimura T 2004 Photoperiodic regulation of type 2 deiodinase gene in djungarian hamster: possible homologies between avian and mammalian photoperiodic regulation of reproduction. Endocrinology 145 1546-1549. (doi:10.1210/en.2003-1593)

Wiersinga WN 2014 Paradigm shifts in thyroid hormone replacement therapies for hypothyroidism. Nature Reviews Endocrinology 10 164-174. (doi:10.1038/nrendo.2013.258)

Wilson FE \& Reinert BD 2000 Thyroid hormone acts centrally to programme photostimulated male American tree sparrows (Spizella arborea) for vernal and autumnal components of seasonality. Journal of Neuroendocrinology 12 87-95. (doi:10.1046/j.13652826.2000.00437.x)

Yamamura T, Hirunagi K, Ebihara S \& Yoshimura T 2004 Seasonal morphological changes in the neuro-glial interaction between gonadotrophin-releasing hormone nerve terminals and glial endfeet in Japanese quail. Endocrinology 145 4264-4267. (doi:10.1210/ en.2004-0366)

Yasuo S, Watanabe M, Obayashi N, Ebihara S \& Yoshimura T 2003 Circadian clock genes and photoperiodism: comprehensive analysis of clock gene expression in the mediobasal hypothalamus, the suprachiasmatic nucleus, and the Pineal gland of Japanese quail

Published by Bioscientifica Ltd. 
under various light schedules. Endocrinology 144 3742-3748. (doi:10.1210/en.2003-0435)

Yasuo S, Watanabe M, Nakao N, Takagi T, Follett BK, Ebihara S \& Yoshimura T 2005 The reciprocal switching of two thyroid hormoneactivating and -inactivating enzyme genes is involved in the photoperiodic gonadal response of Japanese quail. Endocrinology 146 2551-2554. (doi:10.1210/en.2005-0057)

Yasuo S, Nakao N, Ohkura S, Iigo M, Hagiwara S, Goto A, Ando H, Yamamura T, Watanabe M, Watanabe T, et al. 2006 Long-day suppressed expression of type 2 deiodinase gene in the mediobasal hypothalamus of the Saanen goat, a short-day breeder: implication for seasonal window of thyroid hormone action on reproductive neuroendocrine axis. Endocrinology 147 432-440. (doi:10.1210/ en.2005-0507)

Yasuo S, Yoshimura T, Ebihara S, Kolf HW 2009 Melatonin transmits photoperiodic signals through the MT1 melatonin receptor. Journal of Neuroscience 29 2885-2889. (doi:10.1523/ JNEUROSCI.0145-09.2009)

Yoshimura T, Yasuo S, Watanabe M, Iigo M, Yamamura T, Hirunagi K \& Ebihara S 2003 Light-induced hormone conversion of $\mathrm{T}_{4}$ to $\mathrm{T}_{3}$ regulates photoperiodic response of gonads in birds. Nature $\mathbf{4 2 6}$ 178-181. (doi:10.1038/nature02117)

Received in final form 24 March 2016 Accepted 11 April 2016

Accepted Preprint published online 11 April 2016
Published by Bioscientifica Ltd. 